\title{
Chronic disease knowledge and its determinants among chronically ill adults in rural areas of Shanxi Province in China: a cross-sectional study
}

\author{
Miaomiao $\operatorname{Tian}^{\dagger}$, Yingchun Chen ${ }^{\dagger}$, Rui Zhao, Li Chen, Xi Chen, Da Feng and Zhanchun Feng ${ }^{*}$
}

\begin{abstract}
Background: Chronic disease knowledge is an important prerequisite for an individual to implement behavioural changes towards the prevention and control of chronic diseases (CDs). Limited information is available about the relationship between different levels of health services and CD knowledge among rural residents with CDs. This research explores the distribution characteristics of $C D$ knowledge and its determinants among chronically ill adults in rural China according to the aspects of patients and health service providers.
\end{abstract}

Methods: A cross-sectional study was undertaken to estimate distribution characteristics of CD knowledge and collect data of socio-demographic characteristics, healthcare institutions attendances, duration of illness, and family history of CDs. Participants were 1060 rural adults with hypertension or type II diabetes. Correct responses to 12 questions were summed into a total knowledge score, and participants were divided into an adequate health knowledge group (score $\geq 6$ ) or an inadequate health knowledge group (score $<5$ ). Logistic regression was used determine the predictors of adequate CD health knowledge.

Results: The mean age of participants was 61.34 years ( $S D=10$ years). Out of a possible 12 , the median score on the CD knowledge questionnaire was 3.0. About 25\% of participants were classified as having adequate CD knowledge. Those who had a family history and/or long duration of CDs were more likely to have adequate health knowledge. Participants who received CD health information and self-care instructions from their physicians had 2.67 and 13.34 times greater odds of possessing adequate health knowledge than those who received no information, respectively. Adequate CD knowledge was strongly associated with regular check-ups, especially for those who attended township hospitals $(O R=40.17)$.

Conclusions: Having regular check-ups at a fixed healthcare institution and receiving health information from physicians are important measures for increasing CD knowledge among rural adults with CDs. Township hospitals are the most effective settings for health education. It is important to develop an effective community-based prevention and control mechanism for CDs. This requires township hospitals to take a leading role in improving CD knowledge among chronically ill patients, and enhancing implementation of health education in rural China.

\section{Background}

Chronic diseases (CDs) are the leading global causes of death, and they are concentrated in the world's low- and middle-income populations. CDs were responsible for 36 million of the 57 million deaths that occurred globally in 2008 , and mainly comprised cardiovascular diseases, cancers, and diabetes. Nearly $80 \%$ of CD deaths occur in

\footnotetext{
* Correspondence: zcfeng@mails.tjmu.edu.cn

† Contributed equally

School of Medicine and Health Management, Huazhong University of Science and Technology, Wuhan, Hang Kong Road, China
}

low- and middle-income countries [1]. In 2008, data of the Fourth Chinese National Health Services Survey showed that 270 million Chinese people were diagnosed with at least one chronic disease, and about $82 \%$ of deaths and $70 \%$ of disability-adjusted life years lost were caused by CDs. By 2020, it is predicted that the number of deaths attributable to CDs will rise to $85 \%$ [2]. The rapidly growing burden of chronic illnesses in low- and middle-income countries threatens the health condition of their population and their economic development. Because most health-care costs must be paid by patients 
out of their own income in these countries, the cost of health care for CDs creates significant strain on household budgets. Each year, an estimated 100 million people are pushed into poverty because they have to pay directly for health services [1,3]. In China, indirect economic loss caused by CDs was $4.1 \%$ of GNP in 2000, and rural residents have taken $65 \%$ more economical risk of CDs than urban residents. Rural people had greater likelihood of impoverishment cause of treatment of CDs [4].

CDs are diseases of long duration and generally slow progression that are largely preventable through the reduction of their main lifestyle risk factors, such as unhealthy diet, physical inactivity, tobacco use, and harmful use of alcohol [5]. Research shows that increasing the health knowledge of chronically ill and high-risk populations is the most effective way to prevent and delay the onset of CDs [6,7]. The improvement of health knowledge contributes to an increased awareness of health care, which not only helps people know more about diseases and increases their ability for self-care, but also helps them to quit unhealthy behaviours and lead healthy lifestyles. In rural China, health care providers are the main disseminators of health knowledge. Compared with urban residents, in 2008, the rural population had a lower educational level with $18.9 \%$ of them illiterate and $69.2 \%$ not having attended senior middle school. Accessing the rural population for the purpose of providing health information is difficult. Most of them obtain health knowledge mainly from the television and their physicians, but there is no systematic television broadcast of health information [2]. Therefore, the most effective way to improve rural residents' health knowledge and encourage health behaviour is through heath education and promotion.

Trying to prevent, control, and curb the growth trend of CDs in rural areas is a main activity of the Ministry of Health of China. More than half of the Chinese population (53.41\% of 1.3 billion in 2009 [8]), still live in rural areas where residents cannot access the same level of health services as their urban counterparts, which is partly because of a lower level of economic growth, lack of amenities, and poor health service capacity in rural areas [9]. In 2008, the prevalence of CDs in rural China was $17.1 \%$, a $5 \%$ increase on the 2003 prevalence, which is a faster rate of increase than that observed in the urban population (24\% in 2003, $28.3 \%$ in 2008) [10]. Shanxi Province is an example of a large middle-income province of China that is located in north China. It has a population of 33.92 million, of which $55.97 \%$ live in rural areas. Heart attack, cancer, stroke, diabetes, and chronic obstructive pulmonary disease are now the leading causes of death in rural areas among middle-aged and elderly people, and represent a major burden on $\mathrm{CD}$ prevention and control.
In China, county hospitals, town hospitals, and village clinics compose the three-tier rural health service network. They are the principal providers of health care services to rural residents to maintain their health. They are also responsible for CD prevention and control. Compared with countries that implement a family physician practice system of primary health care [11], Chinese citizens can choose to have their check-ups at any hospital (i.e. village clinic, community health services centre, municipal hospital, or provincial hospital). It was reported that $81.7 \%$ of rural residents preferred to obtain health care services from village clinics and town hospitals [12]. Therefore, primary health care institutions are the major 'health keepers' for rural residents. Research shows that the health service capabilities of health institutions, to some extent, determines the health level of local residents; which is influenced by disease treatment, public health services, and health promotion and education, with the latter having an enormous influence on people's level of health knowledge [13,14].

So far, most investigations of the factors contributing to CD-related knowledge among chronically ill adults mainly focused on the characteristics of patients instead of health providers. It has been demonstrated that educational level, occupation, rural/urban statuses of residence, and region of residence were risk factors for inadequate or low $C D$ knowledge [15-19]. American researchers have confirmed that the receipt of health knowledge from different health care providers (practitioners, nurses, diabetes educators, physicians or pharmacists) was a key contributor to one's health knowledge [20]. Yet, to our knowledge, there are no studies analysing the influence of health institution services on the health knowledge of chronically ill adults in China. Therefore, we set out to assess the determinants of CD knowledge from the perspectives of both patients and health providers, and analyse the influence of health care services (of the three-tier rural health institutions) on the health knowledge of rural residents with CDs. Specifically, our research questions are: (1) How is CD knowledge distributed among chronically ill rural residents? (2) What are the potentially modifiable factors associated with $\mathrm{CD}$ knowledge? (3) What is the influence of different health institutions on CD knowledge among rural adults with CDs? A cross-sectional survey was used to answer these questions.

\section{Methods \\ Study population}

The data were collected using a cross-sectional survey conducted in July 2009. We chose Shanxi Province as the study site because chronic disease screening was undertaken in this area during March-June of 2009 [21]. The province consists of 11 cities with 85 counties, and 23 county-level cities that are geographically divided into 
2 strata, as urban, or rural regions. Using a stratified multi-stage sampling method, 4 cities in the urban region, 4 counties, 12 townships, and 36 villages in the rural region were selected following the sequence of district-block-residential area. We selected 30 chronically ill adults from each village from the eligible candidates listed in health records, which were divided into three groups according to the distance from home to the village clinic, and 10 samples were randomly selected from each group. The eligible candidates were defined as those who had been diagnosed with hypertension or type II diabetes (T2D) by physicians, and aged older than 18 years. A total of 1060 rural residents with hypertension or T2D aged from 30-80 years were randomly sampled from 36 villages, and all participants completed a CD survey, including a section on health knowledge. The majority of participants (874) were diagnosed with hypertension, and 186 participants were diagnosed with T2D.

All participants were interviewed in person, and the study purpose was explained to them by the interviewers. Students from the School of Medicine and Health Management of Tongji Medical College and staff of local health care institutions were recruited and trained as interviewers. Items and response choices were read to participants who had difficulty reading (because of illiteracy or poor vision).

This study was approved by the Ethics Committee of Tongji Medical College, Huazhong University of Science and Technology (IORG No: IORG0003571) and informed consent was obtained from all participants in the study.

\section{Questionnaire}

The questionnaire was delivered in simplified Chinese and contained a combination of open- and closed-ended questions (true/false format). It consisted of three parts: socio-demographic information, CD health knowledge, and the ways of receiving health knowledge. Participants were also asked questions about their duration of illness (hypertension/T2D), family history of CDs, and the health institutions they attended for regular check-ups (usually once a month) (Additional file 1).

Socio-demographic information collected included sex, age, educational level, marital status, and employment status.

Health knowledge items were developed by referring to the National Health Promotion Project for Hundreds of Millions of Chinese Farmers (NAHPF) [21], which was launched by the Ministry of Health of China in 2006. We selected all items about CDs from the NAHPF item pool and classified them into 3 groups: basic knowledge (including normal adult blood pressure range for participants with hypertension; normal adult glucose range for participants with diabetes), the risk factors for CDs (6 questions), and daily self-care techniques (5 questions). With the exception of the basic knowledge questions, which had an open response, the response options were: "true", "false", and "don't know".

Sources of health information included the participant's means of receiving health knowledge, and the fixed health institution that participants attended for regular check-ups.

\section{Statistical methods}

All data were entered in duplicate into the EpiData Info version 3.1 database and statistics program (Atlanta, Georgia, USA), and data entry screens were used to revise incorrect entries (i.e. logic errors, input errors). Statistical analysis was performed using PASW statistics 18.0 (SPSS, Chicago, IL, USA).

The overall $\mathrm{CD}$ knowledge score was determined based on the sum of correct answers to 12 health knowledge questions. Each correct answer received one point. Incorrect, missing answers, or the answer "don't know" were awarded no points. According to the goal of NAHPF in 2010 [22] and the level of CD-related health knowledge among rural residents in Shandong (about $35 \%$ in 2007) and Anhui province (about 37\% in 2008), which had a similar GDP to Shanxi province, we defined the cut-off score for adequate versus inadequate knowledge as 6 points (more than 50\% correct answers) $[23,24]$. Those at/or above the cut-off score (6 or more items answered correctly) were considered to have adequate health knowledge, and those below it (5 or fewer correct responses) we considered to have inadequate knowledge.

Socio-demographic characteristics, duration of illness (hypertension/T2D), means of receiving health information, CD health knowledge, and regularly-attended health institutions were summarized using descriptive statistics. Prior to developing logistic regression analysis of the predictors of $\mathrm{CD}$ health knowledge, Chi-square and Fisher's exact tests (where appropriate) were used to explore differences in values of the covariates between the adequate and inadequate health knowledge groups for the purpose of selecting meaningful variables for regression ( $\mathrm{p}$-value $<0.05$ ). Binary logistic regression analysis was used to model the probability of participants having adequate $C D$ health knowledge. The dependent variable was whether (1) or not (0) each participant had adequate $C D$ health knowledge. Independent variables included: sex, age, educational level, duration of illness (hypertension/T2D), family history of CDs, regular attendance at health institutions, and whether health information and self-care instruction was received. All reported p-values are two-sided, and statistical significance level $(\alpha)$ was set at 0.05 . 


\section{Results}

\section{Socio-demographic characteristics of participants}

Participants were predominantly middle-aged or older and had a mean age of 61.34 years $(S D=10.04$ years, range 30-90 years) with the majority being female (67.9\%). More than 70\% of participants were at/or below elementary educational level. Nearly one third of them (32.74\%) had a family history of CDs (hypertension or diabetes). Other socio-demographic information is presented in Table 1.

\section{CD health knowledge}

Out of a possible score of 12, the mean and standard deviation of number of correct answers was 3.90 and 3.21 respectively. The median number of items answered correctly was three. Seventeen participants (1.6\%) responded correctly to all health knowledge questions. The number of respondents who had adequate CD health knowledge (i.e. six or more correct items) was $266(25.1 \%)$. The mean number of correct items' of the adequate knowledge group was 8.56 , and that of the inadequate knowledge group was 2.34 .

Slightly less than $40 \%$ of rural participants with hypertension knew the normal blood pressure range of healthy adults, and only $11.8 \%$ of participants with diabetes knew the normal adult glucose range. Two thirds of participants $(77.26 \%)$ knew that patients with CDs could control their diseases by following their physicians' medical orders. However, only $15.28 \%$ recognized that losing weight was a normal way to control CDs.

\section{The ways of receiving health knowledge}

The main ways that rural participants received CD health knowledge were from physicians, television programs, family members, or neighbours $(81.32 \%, 17.64 \%$, $16.98 \%$ and $12.92 \%$, respectively). Of the $75.00 \%$ of participants who wanted to share their CD knowledge with other people, $95.85 \%$ wanted to share it with family members, $77.99 \%$ with their neighbours and $55.73 \%$ with other chronically ill people. About $12.83 \%$ of participants would like to spread CD knowledge to all people in the region. Overall, physicians were the main sources of health knowledge, and chronically ill adults are willing disseminators of CD knowledge. Health information about CDs (i.e. risk factors, and how long to measure blood pressure or blood glucose) from physicians was received by $60.1 \%$ of participants, and 763 reported that physicians had given them self-care instructions (i.e. stop smoking, do physical exercise, diet control) for daily life.

Regular receipt of health care services at a fixed health institution (usually once a month) was reported by 860 rural chronically ill adults. Among them, 54.77\% saw a physician at village clinics, $30.81 \%$ attended township
Table 1 Socio-demographic characteristics of rural adults with CDs in Shanxi Province of China

\begin{tabular}{|c|c|c|}
\hline Characteristics & $\begin{array}{l}\text { Participants } \\
(\mathrm{n}=1060)\end{array}$ & $\begin{array}{c}\text { Percent } \\
(\%)\end{array}$ \\
\hline \multicolumn{3}{|l|}{ Gender } \\
\hline Male & 340 & 32.10 \\
\hline Female & 720 & 67.90 \\
\hline \multicolumn{3}{|l|}{ Age } \\
\hline $30-39$ & 19 & 1.79 \\
\hline $40-49$ & 101 & 9.53 \\
\hline $50-59$ & 311 & 29.34 \\
\hline $60-69$ & 386 & 36.42 \\
\hline $70-$ & 243 & 22.92 \\
\hline \multicolumn{3}{|l|}{ Education level } \\
\hline less than 6 years elementary study & 398 & 37.50 \\
\hline Elementary & 365 & 34.40 \\
\hline Middle school & 236 & 22.30 \\
\hline high school and above & 61 & 5.80 \\
\hline \multicolumn{3}{|l|}{ Chronic diseases } \\
\hline Hypertension & 874 & 82.50 \\
\hline Diabetes & 186 & 17.50 \\
\hline \multicolumn{3}{|l|}{ Marital Status } \\
\hline Unmarried & 11 & 1.00 \\
\hline Married & 878 & 82.80 \\
\hline Divorced & 7 & 0.70 \\
\hline Widowed & 164 & 15.50 \\
\hline \multicolumn{3}{|l|}{ Occupation } \\
\hline Farmer & 724 & 68.30 \\
\hline migrant worker $^{a}$ & 19 & 1.80 \\
\hline self-employed $^{\text {b }}$ & 15 & 1.40 \\
\hline factory workers & 90 & 8.50 \\
\hline no work & 212 & 20.00 \\
\hline \multicolumn{3}{|l|}{ Family history of chronic diseases } \\
\hline Yes & 347 & 32.74 \\
\hline no & 713 & 67.26 \\
\hline \multicolumn{3}{|l|}{ Length of illness(hypertension/T2D) } \\
\hline $1-5$ & 523 & 49.34 \\
\hline $6-10$ & 316 & 29.81 \\
\hline $11-15$ & 118 & 11.13 \\
\hline $16-$ & 103 & 9.72 \\
\hline
\end{tabular}

Note: a. migrant worker means the rural people leave their villages and go into the cities to do an off-farm work. b. self-employment labourers refer to people who run a private small-scale business by themselves, such as vendors, food-shop owners, repair-shop owners and rice-noodle sellers

hospitals, and $14.42 \%$ attended county hospitals. However, the distribution of participants across the three types of health care providers was different for each of the health knowledge groups. Of the participants with adequate health knowledge, $73.3 \%$ attended township hospitals, which was far more than people with 
inadequate health knowledge (8.8\%). Among the inadequate health knowledge group, more than half of the rural chronically ill adults (55.9\%) attended village clinics, and $24.9 \%$ of these participants did not have regular check-ups at fixed medical institutions. There was a significant difference between the two groups distribution across the health care providers, tested by a chisquare test with $p<0.01$.

\section{Factors affecting CD health knowledge among adults with hypertension or T2D}

Results of univariate analyses indicated that socio-demographic characteristics including age, marital status, education level, and duration of illness had significant relationships with adequate $\mathrm{CD}$ health knowledge (all p-values $<0.05)$. Regular healthcare from fixed health institutions, and receipt of CD-related health and self-care information from physicians were also correlated with CD health knowledge (all p-values < 0.001) (Table 2).

With the exception of sex, all variables were tested for association with CD health knowledge status using multivariate logistic regression. Results indicated that age was the only socio-demographic variable that was significantly associated with $\mathrm{CD}$ health knowledge, with older people being more likely to have adequate knowledge. With increasing duration of $\mathrm{CD}$, participants were more likely to have adequate health knowledge. Meanwhile, rural residents who had a family history of CDs had 1.97 times the odds of having adequate health knowledge than those with no family history $(\mathrm{OR}=1.966,95 \% \mathrm{CI}=1.311-3.04, p=$ 0.001) (Table 3).

Having regular check-ups in a fixed health care institution was positively associated with adequate CD health knowledge. Among the three-tiers of health care institutions, participants that attended township hospitals as their fixed healthcare institution had nearly 40 times the odds of having adequate health knowledge than those who did not see a physician regularly $(\mathrm{OR}=40.173,95 \% \mathrm{CI}=$ 8.646-186.654, $p<0.001)$. Those who attended county hospitals 6.62 times greater odds $(\mathrm{OR}=6.616,95 \% \mathrm{CI}=$ $1.383-31.644, p=0.018$ ) of having adequate health knowledge compared with those who did not see a physician regularly. Interestingly, participants attending village clinics showed no significant difference in likelihood to have adequate health knowledge than those who did not see a physician regularly $(\mathrm{OR}=1.159,95 \% \mathrm{CI}=0.249$ $5.384, p=0.851$ ). Participants who had received CD health information from their physicians had 2.67 times greater odds of having adequate health knowledge than those did not receive $C D$ health information $(\mathrm{OR}=2.671,95 \% \mathrm{CI}=$ 1.333-5.350, $p<0.001)$. Also, participants that received self-care instructions from physicians had 13.34 times greater odds of having adequate CD knowledge than those who received no instructions $(\mathrm{OR}=13.340,95 \% \mathrm{CI}=$ 3.634-48.972, $p<0.001$ ) (Table 3).

\section{Association between receiving health information and CD health knowledge}

The type of health care institution regularly attended by chronically ill rural residents, and the receipt of health information and self-care instructions from physicians had a strong joint effect on CD health knowledge (Table 4). Among 265 participants who had regular check-ups in township hospitals, 249 (93.96\%) self-reported that they had received health information from physicians, and 255 (96.23\%) received self-care instructions, and about $76 \%$ of them belonged to the adequate $C D$ health knowledge group. However, among 471 participants who had regular check-ups in village clinics, 233 (49.47\%) had received health information from their physicians $(8.15 \%$ of them scored $\geq 6)$ and $372(79 \%)$ received self-care instructions (7\% of them scored $\geq 6$ ).

The proportions of participants who received health information and self-care instructions from county hospitals were around $86 \%$, and about $39 \%$ of them were classified as having adequate CD health knowledge. Those who had not attended regular check-ups in a fixed health institution had the lowest potential to receive health knowledge from physicians, and were thus less likely to have adequate CD health knowledge.

\section{Discussion}

More than $70 \%$ of participants in our study had inadequate $C D$ heath knowledge, including the highly educated rural participants who had high school education or higher. Participants had a higher level of basic CD knowledge than professional knowledge. For example, they know about the normal blood pressure range of healthy adults, and disease control through smoking cessation and reasonable alcohol consumption, but few of them know about hyperglycaemia and hyperlipidaemia as risk factors for hypertension (with only $17.36 \%$ of them answering correctly), and that weight loss is a means of disease control (with just 15\% answering correctly). These finding are consistent with studies conducted in other provinces of China [24-26].

As is indicated in the multivariate model, participants who had a longer duration of CDs, and those who had a family history of CDs were more likely to have adequate $\mathrm{CD}$ health knowledge, which may have led to increased attention on disease control for themselves and their family members over time. In such circumstances, they may have been more willing to see physicians and obtain health information and self-care instructions from them than people without a family history of $C D$, or with a short duration of CD. 
Table 2 Univariate analyses examining factors associated with adequate health knowledge in rural chronically ill adults

\begin{tabular}{|c|c|c|c|c|c|c|}
\hline \multirow[t]{2}{*}{ Predictor } & \multicolumn{2}{|c|}{$\begin{array}{l}\text { Group of adequate } \\
\text { health knowledge } \\
\qquad(n=266)\end{array}$} & \multicolumn{2}{|c|}{$\begin{array}{l}\text { Group of inadequate } \\
\text { health knowledge } \\
(n=794)\end{array}$} & \multirow[t]{2}{*}{$\chi^{2}$} & \multirow[t]{2}{*}{$P$} \\
\hline & $\mathrm{N}$ & $\%$ & $\mathrm{~N}$ & $\%$ & & \\
\hline \multicolumn{7}{|l|}{ Sex } \\
\hline male & 92 & 34.6 & 248 & 31.2 & & \\
\hline female & 174 & 65.4 & 546 & 68.8 & 1.028 & 0.311 \\
\hline \multicolumn{7}{|l|}{ Age } \\
\hline$<50$ & 30 & 11.3 & 90 & 11.3 & & \\
\hline $50-59$ & 84 & 31.6 & 227 & 28.6 & & \\
\hline $60-69$ & 113 & 42.5 & 273 & 34.4 & & \\
\hline $70-$ & 39 & 14.7 & 204 & 25.7 & 15.791 & 0.003 \\
\hline \multicolumn{7}{|l|}{ Marital Status } \\
\hline Unmarried & 4 & 1.5 & 7 & 0.9 & & \\
\hline Married & 234 & 88 & 644 & 81.1 & & \\
\hline Divorced & 2 & 0.8 & 5 & 0.6 & & \\
\hline Widowed & 26 & 9.8 & 138 & 17.4 & 9.371 & 0.025 \\
\hline \multicolumn{7}{|l|}{ Education level } \\
\hline less than 6 years elementary study & 80 & 30.1 & 318 & 40.1 & & \\
\hline Elementary & 92 & 34.6 & 273 & 34.4 & & \\
\hline Middle school & 72 & 27.1 & 164 & 20.7 & & \\
\hline beyond high school & 22 & 8.3 & 39 & 4.9 & 12.869 & 0.005 \\
\hline \multicolumn{7}{|l|}{ Duration of illness } \\
\hline $1-5$ & 114 & 42.9 & 403 & 50.8 & & \\
\hline $6-10$ & 81 & 30.5 & 235 & 29.6 & & \\
\hline $11-15$ & 46 & 17.3 & 78 & 9.8 & & \\
\hline $16-$ & 25 & 9.4 & 78 & 9.8 & 12.138 & 0.007 \\
\hline \multicolumn{7}{|l|}{ The place participants received health care regularly } \\
\hline Village Clinics & 27 & 10.2 & 444 & 55.9 & & \\
\hline township hospitals & 195 & 73.3 & 70 & 8.8 & & \\
\hline County Hospitals & 42 & 15.8 & 82 & 10.3 & & \\
\hline participants who do not check up regularly in clinics or hospitals & 2 & 0.8 & 198 & 24.9 & 492.274 & $<0.001$ \\
\hline \multicolumn{7}{|l|}{ Family history of chronic diseases } \\
\hline yes & 138 & 51.9 & 260 & 32.7 & & \\
\hline no & 128 & 48.1 & 534 & 67.3 & 31.109 & $<0.001$ \\
\hline \multicolumn{7}{|l|}{ Received health information related to chronic diseases from doctors } \\
\hline yes & 252 & 94.7 & 385 & 48.5 & & \\
\hline no & 14 & 5.3 & 409 & 51.5 & 177.712 & $<0.001$ \\
\hline \multicolumn{7}{|l|}{$\begin{array}{l}\text { Received self-care instructions } \\
\text { from doctors }\end{array}$} \\
\hline yes & 263 & 98.9 & 500 & 63 & & \\
\hline no & 3 & 1.1 & 294 & 37 & 127.325 & $<0.001$ \\
\hline
\end{tabular}

Note: adequate health knowledge of CDs $=$ answer at and more than 6 items correctly

Our findings convince us that those who receive health information and self-care instructions from their physicians are more likely to have adequate CD health knowledge. The information in Table 3 reveals that adequate $\mathrm{CD}$ health knowledge among the respondents was associated with receiving health care from regularlyattended fixed health institutions. We also identified a significant relationship between the health services of 
Table 3 Multivariable analyses examining factors associated with adequate health knowledge in rural chronically ill adults

\begin{tabular}{|c|c|c|c|c|c|}
\hline Predictor & Reference category & B & $\mathbf{P}$ & OR & $95 \% \mathrm{Cl}$ \\
\hline Age & $<50$ & & & & \\
\hline $50-59$ & & 0.491 & 0.159 & 1.633 & $(0.825,3.232)$ \\
\hline $60-69$ & & 0.981 & 0.006 & 2.667 & $(1.326,5.366)$ \\
\hline $70-$ & & 0.422 & 0.337 & 1.525 & $(0.645,3.606)$ \\
\hline Marital Status & Unmarried & & & & \\
\hline Married & & 0.416 & 0.631 & 1.515 & $(0.278,8.245)$ \\
\hline Divorced & & 0.470 & 0.767 & 1.601 & $\begin{array}{l}(0.071 \\
36.010)\end{array}$ \\
\hline Widowed & & 0.269 & 0.770 & 1.309 & $(0.215,7.958)$ \\
\hline Education level & Less than 6 years elementary study & & & & \\
\hline Elementary & & -0.425 & 0.110 & 0.654 & $(0.389,1.101)$ \\
\hline Middle school & & 0.057 & 0.847 & 1.059 & $(0.591,1.898)$ \\
\hline Beyond high school & & 0.032 & 0.942 & 1.033 & $(0.433,2.463)$ \\
\hline Duration of illness & $1-5$ & & & & \\
\hline $6-10$ & & -0.102 & 0.679 & 0.903 & $(0.558,1.463)$ \\
\hline $11-$ & & 0.697 & 0.013 & 2.007 & $(1.161,3.469)$ \\
\hline Family history of chronic diseases & no & 0.691 & 0.001 & 1.966 & $(1.311,3.041)$ \\
\hline $\begin{array}{l}\text { The place participants received health care } \\
\text { regularly }\end{array}$ & $\begin{array}{c}\text { Participants who do not check up regularly in clinics or } \\
\text { hospitals }\end{array}$ & & & & \\
\hline Village Clinics & & 0.148 & 0.851 & 1.159 & $(0.249,5.384)$ \\
\hline Township hospitals & & 3.693 & 0.000 & 40.173 & $\begin{array}{c}(8.646, \\
186.654)\end{array}$ \\
\hline County Hospitals & & 1.889 & 0.018 & 6.616 & $\begin{array}{l}(1.383 \\
31.644)\end{array}$ \\
\hline $\begin{array}{l}\text { Received health information related to chronic } \\
\text { disease }\end{array}$ & $\begin{array}{l}\text { Have not received health information related to chronic } \\
\text { diseases }\end{array}$ & 0.982 & 0.006 & 2.671 & $(1.333,5.350)$ \\
\hline Received self-care instruction from doctors & Have not received self-care instruction from doctors & 2.591 & 0.000 & 13.340 & $\begin{array}{l}(3.634 \\
48.972)\end{array}$ \\
\hline
\end{tabular}

Note: adequate health knowledge of CDs $=$ answer at and more than 6 items correctly

different health institutions and the CD knowledge of participants who had regular check-ups.

As part of the Chinese Health System Reform (initiated in 2009), CD management and health education are main components of basic public health services, and are at the top of the policy agenda for rural health [27]. The Ministry of Health has outlined the main responsibilities of each level of health institution for CD prevention and control.
Village clinics, the basic part of the rural health care system, are responsible for providing basic outpatient diagnosis and treatment, basic public health care including health education and medication management, and long-term monitoring for patients with CDs. In addition to supplying health care services to patients with CDs, township hospitals are also obligated to help to build and maintain health records, conduct health education and promotion, and

Table 4 Association between health institutions and CD health knowledge

\begin{tabular}{|c|c|c|c|c|c|c|c|c|c|c|c|c|c|}
\hline \multirow[t]{2}{*}{ Health institutions } & \multirow{2}{*}{$\begin{array}{c}\text { Participants } \\
\text { N }\end{array}$} & \multicolumn{2}{|c|}{$\begin{array}{l}\text { Received health } \\
\text { information related to } \\
\text { CDs from doctors }\end{array}$} & \multicolumn{2}{|c|}{ Group1* } & \multicolumn{2}{|c|}{ Group2** } & \multicolumn{2}{|c|}{$\begin{array}{l}\text { Received self-care } \\
\text { instructions from } \\
\text { doctors }\end{array}$} & \multicolumn{2}{|c|}{ Group1* } & \multicolumn{2}{|c|}{ Group2** } \\
\hline & & $\mathrm{N}$ & $\%$ & $\mathrm{~N}$ & $\%$ & $\mathrm{~N}$ & $\%$ & $\mathrm{~N}$ & $\%$ & $\mathrm{~N}$ & $\%$ & $\mathrm{~N}$ & $\%$ \\
\hline Village clinics & 471 & 233 & 49.47 & 19 & 8.150 & 214 & 91.85 & 372 & 78.98 & 26 & 6.99 & 346 & 93.01 \\
\hline Township hospitals & 265 & 249 & 93.96 & 191 & 76.71 & 58 & 23.29 & 255 & 96.23 & 195 & 76.47 & 60 & 23.53 \\
\hline County hospitals & 124 & 109 & 87.90 & 42 & 38.53 & 67 & 61.47 & 105 & 84.68 & 41 & 39.05 & 64 & 60.59 \\
\hline No fixed health institutions ${ }^{a}$ & 200 & 46 & 23.00 & 0 & 0 & 46 & 100 & 31 & 15.50 & 1 & 3.23 & 30 & 96.77 \\
\hline
\end{tabular}

Note: a. no fixed health institutions mean that participants do not see a doctor regularly in a fixed health institution. ${ }^{*}$ the group of participants having adequate health knowledge of CDs. ${ }^{* *}$ the group of participants having inadequate health knowledge of CD 
supply service guidance and technical training for village clinics. County hospitals, as the medical centre for a county area, also have a responsibility to provide service and technical guidance for township hospitals and village clinics.

According to our findings, township hospitals have the most positive influence on $\mathrm{CD}$ knowledge for rural chronically ill residents among the three-tier rural health care institutions. Almost all participants in township hospitals (93.96\%) received health education and promotion services; and most of them had significantly higher scores of CD knowledge. While more than half of the participants attending village clinics self-reported that they had received such services from village physicians, less than $10 \%$ of them had adequate CD health knowledge. This disappointing finding may be partially attributable to a low capacity of health care supply and a chronic inadequateness of public health care services among village clinics. Village clinics are subject to a lack of health infrastructure, and low educational levels of their health faculty.

It is reported that nearly $90 \%$ of village physicians are below vocational educational level, and one third of them practice without a degree [28]. Most of them lack knowledge about CD prevention and control, so it is difficult for them to provide health knowledge to patients. Moreover, most village clinics set up by village or township hospitals are operated as small businesses, although the actual facilities may be owned by the government [29]. In rural areas, nearly $36 \%$ of village clinics are privately run and do not offer public health services to rural residents for two main reasons [12]. First is the lack of relevant professional training and equipment available to these practitioners, and the influence this has on the overall quality of health services they provide. The second reason is that a lack of government funding discourages them from paying adequate attention to public health services such as health education and promotion [30].

County hospitals are the centres of medical and technical guidance and training for a county, yet seem to provide less effective health education services than township hospitals. This disparity may be attributable to the heavy burden of diagnosis and treatment of diseases at county hospitals. It was reported in "An Analysis Report of National Health Services Survey in China 2008 " that clinicians mainly focused on curing diseases and reversing the unhealthy status of patients, instead of supplying public health care services [31]. In county hospitals, most clinicians are specialists with a high responsibility for managing difficult diseases, and this consumes most of their attention. Therefore, there is no effective coordination of health education, disease prevention and control, and disease therapy for patients [31,32]. Furthermore, because of the profit-oriented nature of county hospitals, physicians pay more attention to disease therapy, which can bring direct economic benefits than to public health care services, and this further contributes to the chronic inadequacy of health education and promotion among county hospitals $[29,33]$.

\section{Conclusions}

Our study highlights the continuing need for greater CD knowledge in the rural areas of China, as well as the positive effects of health care institutions' health education and promotion for rural residents. In addition, our results emphasize the importance of establishing a community based CD prevention and control programme. This would require township hospitals to take a leading role and supply service guidance, technical training, and health supervision to village clinics to increase the quality of public health care services in rural China. Furthermore, efforts should be made to strengthen the basic construction of village clinics, and to develop a team of grass-roots health care workers with the purpose of enhancing health care service capacity in rural areas. Sound supervision of the public health care service system should be established to ensure proper implementation of public health services in rural health institutions.

The sample in this study consists of rural adults with hypertension or $\mathrm{T} 2 \mathrm{D}$, which may or may not represent the chronically ill population. Our data of health knowledge and self-care instructions were based on selfreport, which may be subject to respondent bias. The factors influencing attendance at particular hospitals for rural residents with CDs are complicated, such as distance, economic condition, attitude of physicians, diagnosing and treating environment, qualification of the physicians, and waiting times. Our findings may be influenced by these factors, and we assume that distance and economic conditions are likely to be the main factors of influence for participants in Shanxi Province. Another potential limitation of our research is the use of closed-ended questions (i.e. true/false/don't know) in the health knowledge test, which may have allowed participants to guess the correct answer.

\section{Additional material}

Additional file 1: Part A (Basic personal information), Part B (Health knowledge of chronic diseases) consulted the question pool of the National Health Promotion Project for Hundreds of Millions of Chinese Farmers (NAHPF) and Part C (The ways of receiving health knowledge) of the questionnaire consulted the questionnaires of the Fourth Chinese National Health Services Survey.

List of abbreviations

CDs: chronic diseases; T2D: type II diabetes; NAHPF: National Health Promotion Project for Hundreds of Millions of Chinese Farmers. 


\section{Authors' contributions}

Study concept and design: MT and YC. Data collection: RZ, LC, XC and DF. Statistical analysis: MT, YC and RZ. Analysis and interpretation of data: MT, RZ and XC. Draft of the manuscript: MT and YC. Critical revision of the manuscript for important intellectual content: CF, MT, YC and LC. Administrative, technical, and material support: CF and MT. Study supervision: CF. All authors read and approved the final manuscript.

\section{Competing interests}

The authors declare that they have no competing interests.

Received: 21 July 2011 Accepted: 22 December 2011

Published: 22 December 2011

\section{References}

1. WHO: In Global status report on noncommunicable diseases 2010. Volume 13. WHO Press; 2011:15-16.

2. Center for health statistics and information, MOH: In An Analysis Report of National Health Services Survey in China. Volume 2009. Peking Union Medical College Press; 2008:8-12, 126

3. Yusuf S, Reddy S, Ounpuu S, Anand S: Global burden of cardiovascular diseases: part I: general considerations, he epidemio-logic transition, risk factors, and impact of urbanization. Circ 2001, 104:2746-2753.

4. Hebei government. [http://www.hebei.gov.cn/article/20081218/1118234 $\mathrm{htm}]$, Accessed Dec 18, 2008.

5. WHO: 10 facts on noncommunicable diseases [http://www.who.int/features/ factfiles/noncommunicable_diseases/en/index.html].

6. Rukstalis M, Blosky MA, Steinberg H, Anglade M, Anderer T, Bloom F Jr: Primary care web-based lifestyle intervention for type 2 diabetes: randomized controlled trial to improve knowledge and self-care. Clin Med Res 2011, 9(3-4):164

7. Bergsten U, Bergman S, Fridlund B, Arvidsson A: "Delivering knowledge and advice": Healthcare providers' experiences of their interaction with patients' management of rheumatoid arthritis. Int I Qualitative Stud Health Well-being 2011, 6:8473.

8. National bureau of statistics of China. [http://www.stats.gov.cn/tisj/ndsj/ 2010/indexch.htm]

9. Zimmer $Z$, Kaneda $T$, Spess L: An examination of urban versus rural mortality in China using community and individual data. J Gerontol B Psychol Sci Soc Sci 2007, 62:S349-S357.

10. Center for health statistics and information, MOH: In An Analysis Report of National Health Services Survey in China. Volume 2009. Peking Union Medical College Press; 2008:2-3.

11. Baskerville NB, Hogg W, Lemelin J: Process evaluation of a tailored multifaceted approach to changing family physician practice patterns improving preventive care. J Fam Pract 2001, 50(3):242-249.

12. China health statistical yearbook 2010. [http://www.moh.gov.cn/ publicfiles/business/htmlfiles/zwgkzt/ptjnj/year2010/index2010.html].

13. Liu ZR, Albanese E, Li SR, Huang YQ, Ferri CP, Yan F, Sousa R, Dang WM, Prince $\mathrm{M}$ : Chronic disease prevalence and care among the elderly in urban and rural Beijing, China - a 10/66 Dementia Research Group cross-sectional survey. BMC Publ Health 2009, 9:394-404.

14. Yang J, Guo A, Wang YD, Zhao XH, Li H, Duckitt R, Liang WN: Human resource staffing and service functions of community health services organizations in China. Ann Fam Med 2008, 6(5):421-427.

15. Weinert C, Cudney S, Hill W: Health knowledge acquisition by rural women with chronic health conditions: a tale of two web approaches. Aust J Rural Health 2008, 16(5):302-307.

16. Schillinger D, Grumbach K, Piette J, Wang F, Osmond D: Association of health literacy with diabetes outcomes. J Am Med Assoc 2002, 288(4):475-482.

17. Pakseresht M, Mead E, Gittelsohn J, Roache C, Sharma S: Awareness of chronic disease diagnosis amongst family members is associated with healthy dietary knowledge but not behaviour amongst Inuit in Arctic Canada. J Hum Nutr Diet 2010, 23(1):100-109.

18. Rothman RL, Yin HS, Mulvaney S, Co JP, Homer C, Lannon C: Health literacy and quality: focus on chronic illness care and patient safety. Pediatrics 2009, 124:315-326.

19. Kun Y, Liang H, Zheng L, Ma AG, Li GL, Han XX: Awareness rate of nutrition and chronic disease knowledge and analysis of related influence factors among rural middle-aged and old residents [In chinese]. Chinese Journal of Health Education 2010, 26(5):348-358.

20. Hon K, Bethany J, Kathryn M, Steven D: oral health knowledge and behavior among adults with diabetes. Diabetes Res Clin Pract 2009, 86b:239-246.

21. Health department of Shanxi province: Health yearbook 2010 of Shanxi province. Taiyuan 2010, 192

22. The central people's government of the people's republic of China. [http://www.gov.cn/zwgk/2006-07/24/content_343925.htm].

23. Zhu B, Zhang LZ, Dong H, Ji GP, Hong T, Zu GH: Analysis on current situation of health education and demand among rural residents in Anhui Province [in Chinese]. Health education and health promotion 2007. 2(4):14-16.

24. Li DH: Study on the relevant chronic disease knowledge and behavioral risk factors of rural residents in Shandong Province [in Chinese]. PhD thesis Shandong University. Department of Social science and health management; 2008.

25. Wang XB, Wang LQ, Liu DW, Li JG, Sun JX, Wang BH: Analysis on hypertension KAP and influence factors in rural population [in Chinese]. Chin J Public Health Mar 2008, 24(3):269-270.

26. Hao FR, Qi SH, Jia CX, Zhu YW, Zhao ZT, Zhang Y: the descriptive and analytical study of the awareness rate of diabetes mellitus knowledge in rural population [in Chinese]. Chin J Contr Chron Non-cummun Dis 2002, 10(1):14-16.

27. Implementation Plan for the Recent Priorities of the Health Care System Reform (2009-2011). [http://www.china.org.cn/government/scio-pressconferences/2009-04/09/content_17575401.htm]

28. Center for health statistics and information, MOH: In An Analysis Report of National Health Services Survey in China. Volume 2009. Peking Union Medical College Press; 2008:11.

29. The World Bank: Reforming China's rural health system. Washington D.C 2009, 141:118.

30. Qu JB, Zhang XF, Meng QY, Li LG, Pang XF, Liu YL: An assessment on current situation of village clinics in Shandong Province [in Chinese]. Chinese Health Economics 2006, 25(1):29-31.

31. Center for health statistics and information, $\mathrm{MOH}$. In An Analysis Report of National Health Services Survey in China. Volume 2009. Peking Union Medical College Press; 2008:11-12.

32. Jiang YG: Problems and measures of county level hospital [in Chinese]. Chinese Hospitals 2007, 11(2):76-78.

33. Song HY: Study on medical service flow in rural areas under basic health service system-the case of Shandong province [in Chinese]. PhD thesis Shandong University, Department of Social science and health management; 2010.

\section{Pre-publication history}

The pre-publication history for this paper can be accessed here: http://www.biomedcentral.com/1471-2458/11/948/prepub

\section{doi:10.1186/1471-2458-11-948}

Cite this article as: Tian et al:: Chronic disease knowledge and its determinants among chronically ill adults in rural areas of Shanxi Province in China: a cross-sectional study. BMC Public Health 2011 11:948.

\section{Submit your next manuscript to BioMed Central and take full advantage of:}

- Convenient online submission

- Thorough peer review

- No space constraints or color figure charges

- Immediate publication on acceptance

- Inclusion in PubMed, CAS, Scopus and Google Scholar

- Research which is freely available for redistribution 